\title{
КАК РОССИЯ БОРЕТСЯ С САНКЦИЯМИ, А ЕВРОПА - С ДОЛЛАРОМ
}

\begin{abstract}
Аннотация. Мировое хозяйство вступает в новую эпоху: давление со стороны США заставляет всё большее число стран задумываться о необходимости зашиты своего экономического суверенитета, в том числе посредством сокращения международной роли доллара в пользу более активного использования их наџиональных валют. В России и Европе эти процессы идут параллельными курсами. Велики ли различия в подходах к решению задачи и есть ли условия для объединения усилий Европейского союза и РФ?

Ключевые слова: Европейский союз, Европейская колиссия, евро, Россия, рубль, США, доллар, санкиии, международная валютно-финансовая система.

В ноябре 2018 г. произошло знаковое событие. Согласно рейтингу агентства Bloomberg рубль стал самой рискованной валютой в мире. Этот вывод был сделан экспертами на основе данных о действиях трейдеров, готовых купить и продать ту или иную валюту на рынке. «Пальму первенства» рубль отобрал у турецкой лиры, которая ранее получила её в ходе серьёзного кризиса в отношениях между Анкарой и Вашингтоном в августе 2018 г.

Критическое ухудшение репутации рубля связано с падением на нефтяном рынке и риском наращивания американских санкций. Ещё меньше трейдеры стали доверять рублю после недавнего конфликта на Чёрном море, когда российские пограничники задержали украинские военные корабли, нарушившие государственную границу РФ. В то же время администрация Дональда Трампа сняла часть ограничений с Турции, а центральный банк этой страны предпринял ряд ожидавшихся шагов, в том числе повышение ключевой ставки.
\end{abstract}

\section{Центральный банк и санкции}

Акцент на действиях Центробанка сделан неслучайно. В условиях нарастающего давления внешних шоков роль главного денежно-кредитного регулятора любой страны возрастает по экспоненте. Особенно в том, что касается его способности противостоять этим шокам или, как минимум, нивелировать их негативное влияние на национальное хозяйство.

В Банке России давно говорят о намерении «бороться» с санкциями. Официальная позиция такова: поскольку предугадать действия властей иностранных государств (прежде всего, США) наш банк не в силах, он видит свою задачу в том, чтобы иметь набор инструментов, сглаживающих их последствия. По мнению руководства банка, эти инструменты, в первую очередь, должны помогать экономике адаптироваться к вызываемым санкциями скачкам на рынках, а также ограничивать риски для финансовой стабильности, связанные с наиболее рискованными операциями.

Именно поэтому среди своих «антисанкционных» инструментов Банк России в первую очередь называет ограничение объёмов наиболее рисковых видов кредитования, способных стать катализатором эффекта домино в случае кризиса. ЦБ РФ также работает над созданием

(C) Гусев Кирилл Нионилович - кандидат экономических наук, ведущий научный сотрудник Центра денежнокредитных и валютно- финансовых проблем ИЕ РАН. Адрес: 125009, Россия, Москва, ул. Моховая, д. 11, стр. 3.E-mail: banks- europe@ mail.ru.

DOI: http://dx.doi.org/10.15211/vestnikieran62018 
буферов, защищающих национальную экономику от внешних шоков. Здесь, среди важнейших мер упоминается стимулирование и надзор за созданием коммерческими банками достаточных резервов на случай внешних шоков.

Тема антироссийских санкций постоянно подогревается американскими властями. В частности, муссируется информация о том, что в Конгрессе США на рассмотрении находятся ещё два законопроекта, которые касаются введения антироссийских санкций на новый суверенный долг и госбанки. По оценке ряда экспертов, применение таких санкций способно ввергнуть экономику РФ в рецессию. При этом в силу своей специфики и широкого поля действия подобные санкции затронут уже не только российскую экономику, но и международных инвесторов и европейские страны.

Последнее обстоятельство способно оказаться важным сдерживающим фактором, поскольку ранее Конгрессу США уже представляли экспертное заключение о том, что введение санкций против суверенного долга РФ может иметь негативные последствия для всего международного долгового рынка. Но даже сам факт обсуждения этой идеи американскими законодателями оказывает значительное воздействие на конъюнктуру российского рынка.

Эксперты вышеупомянутого агентства Bloomberg уже подсчитали, что из-за санкций экономика России с 2014 г. могла потерять примерно 6\% роста ВВП ${ }^{1}$. По мнению этих экспертов, в указанный период экономика нашей страны «недобрала» в целом порядка 10\%, из которых только 4\% может быть объяснено падением цен на нефть.

\section{Шоки внешние и внутренние}

Однако на темпы роста ВВП давят не только санкции и падение цен на нефть, но и денежно-кредитная политика Банка России, использующего инфляционное таргетирование в ущерб экономическому росту. И при всей очевидности этой ситуации ЦБ РФ не планирует отказываться от своей жёсткой линии. После недавнего резкого обесценения рубля ключевая ставка была повышена до 7,5\% для обуздания возможного скачка инфляции. И хотя сейчас прогноз по инфляции оптимистичный, ставка остаётся на уровне вдвое выше инфляции, и ЦБ не даёт повода надеяться на её снижение в ближайшее время.

Неактивную позицию занимает Министерство финансов РФ, которое в рамках бюджетного правила изымает в резервы доходы от продаж нефти по цене свыше 40 долларов за баррель. Эти рубли ЦБ конвертирует в валюту, которую размещает за пределами РФ. Всего в 2018 г. на покупку валюты по этой схеме может быть потрачено около 4 трлн рублей, что эквивалентно почти 25\% расходов федерального бюджета.

Имея подобные «излишки», правительство всё равно настояло на повышении в 2019 г. НДС с 18 до 20\%, чтобы получить дополнительные средства на решение поставленных президентом задач национального развития. Использовать вышеупомянутые резервы для этого не планируется, а бюджетное правило продолжит действовать, несмотря на очевидный парадокс: рост налогов повысит инфляцию, с которой ЦБ РФ активно борется.

При этом вероятность дальнейшего падения темпов роста ВВП, кажется, вообще не рассматривается. Правительство официально прогнозирует ускорение экономического роста до $2 \%$ уже в 2020 г., а в 2021 г. - до 3\% и выше. Но далеко не все в экспертном сообществе разделяют этот оптимизм. И, как показано выше, причина не только в том, что санкции и дальше будут негативно влиять на экономику России. По итогам 2018 г. ЦБ РФ прогнозирует темпы роста ВВП на уровне 1,8\%, которые в банке считают близкими к потенциальному. При

\footnotetext{
${ }^{1}$ Bloomberg: санкции «отобрали» у России 6\% ВВП. URL: http://www.banki.ru/news/lenta/?id=10750659 (дата обращения: 06.12.2018).
}

Научно-аналитический вестник ИЕ РАН, 2018, №6 
этом в банке уверены, что повысить темпы роста экономики методами денежно-кредитной политики нельзя. В свою очередь, глава Счётной палаты Алексей Кудрин заявил, что реальные темпы роста российской экономики в последнее десятилетие не превышали $1 \%$, а их потенциальный уровень сейчас не выше $1,6 \%{ }^{1}$.

Агентство $S \& P$ предполагает, что новые антироссийские санкции, если и будут введены, то по-прежнему против конкретных физических лиц, компаний и банков. Однако опыт прошлых лет показывает, что эффект от санкций так или иначе оказывается распределённым на всю отечественную экономику. Активное накопление резервов, которое проводит сейчас Минфин в связке с ЦБ, вероятно, способно стабилизировать экономику (с многочисленными оговорками), но оно точно не является инструментом роста. Последний возможен только, если произойдут качественные изменения в уровне производительности труда. А для этого, в свою очередь, необходима активная инвестиционная политика, предполагающая финансирование рискованных инновационных направлений.

\section{Позиция Банка России}

Сегодня уже ясно, что антироссийские санкции стали уникальным экономическим оружием в руках США, и будут оставаться таковым до тех пор, пока Россия не найдёт реальный способ противодействия, который имел бы столь же серьёзное влияние на экономику США. Одним из направлений повышения международного экономического веса России должно было стать формирование вокруг неё нового интеграционного блока, опирающегося на российский рубль как свою основную валюту.

В этой связи глава Центробанка Эльвира Набиуллина на ноябрьском инвестиционном форуме «Россия зовёт» в Москве заявила, что принуждать участников рынка использовать российскую валюту административными методами никто не будет: «Мы предпринимали и предпринимаем ряд регулятивных мер для того, чтобы банкам было более выгодно работать в рублях и по пассивной стороне и по активной: диверсификация требований по обязательным резервам, коэффициенты риска по валютным кредитам у нас повышены в расчёте достаточности капитала. Но, наверное, самое основное, чтобы рубль был привлекателен для расчётов, - уверенность в том, что покупательная способность рубля не обесценивается, низкая инфляция и, конечно же, низкая волатильность рубля для использования в международных расчётах. Это очень важные факторы»².

Э. Набиуллина также выразила уверенность, что при усилении внешних шоков Банк России сможет сохранить финансовую стабильность. Одним из инструментов, доказавших свою эффективность в этом плане, глава ЦБ назвала приостановку покупки валюты в рамках бюджетного правила. Эти правила как мера правительства в целом, по её мнению, создают буферы от внешних шоков, стабилизируют бюджетные расходы и закладывают основы устойчивости экономики и от колебаний цен на нефть и от санкций. Э. Набиуллина назвала и другие инструменты по поддержанию финансовой стабильности: «это и автоматически включающиеся валютные свопы, аукционные инструменты предоставления валютного рефинансирования нашим банкам, это и временные регулятивные послабления для банков» ${ }^{3}$. Глава ЦБ убеждена, что без жёсткого надзора устойчивую финансовую систему сегодня невозможно построить, но регулирование должно развиваться, чтобы соответствовать новым вызовам

\footnotetext{
${ }^{1}$ Набиуллина оценила потенциал роста экономики к 2021 г. URL: https://www.rbc.ru/rbcfreenews/5bfe51a69a7947 ab61e6b366?from=newsfeed (дата обрашения: 06.12.2018).

${ }^{2}$ Набиуллина рассказала о способе сделать расчёты в рублях привлекательными. URL: https://www.rbc.ru/econo mics/28/11/2018/5bfe4ee19a7947aa7a9c006e?from=main_right (дата обращения: 06.12.2018).

${ }^{3}$ Там же.
} 
и рискам.

Ещё одним потенциально перспективным направлением можно считать размещение облигаций российского правительства в евро. В частности, в ноябре 2018 г., впервые за несколько лет, Минфин России разместил еврооблигации на 1 млрд евро с доходностью 3\% годовых сроком на 7 лет. При этом заявки покупателями были поданы на большую сумму. Решение Минфина размещать бумаги в евро не могло хотя бы отчасти не мотивироваться рисками, связанными с санкциями США. Тем более что ранее аналогичное решение принял «Газпром», который также успешно разместил облигации в евро. Вместе с тем, по данным ЦБ РФ, в структуре внешнего долга России бумаги в евро составляют пока всего 0,2\%.

\section{Европа на шаг впереди}

Пока ЦБ РФ формирует пакет антисанкционных инструментов, а российский рубль ищет пути к своей интернационализации, в ответ на торгово-экономическое противостояние, которое США развязали со всем миром, единая Европа разработала собственный план дедолларизации экономики и повышения международной роли евро.

В сентябре 2018 г. в ежегодном обращении Председатель Европейской комиссии Ж.-К. Юнкер $^{1}$ указал на стратегическую важность евро и необходимость обеспечения того, чтобы эта валюта играла роль, соответствующую статусу ЕС на международной арене.

В развитие этой идеи 5 декабря 2018 г. Европейская комиссия опубликовала доклад «К более сильной международной роли евро» ${ }^{2}$, отметив ${ }^{3}$, что на фундаменте решений по усилению Экономического и Валютного Союза, формированию банковского союза и переходу к союзу рынков капитала, комиссия намерена повышать роль евро до уровня, который бы адекватно отражал политический, экономический и финансовый вес еврозоны в мире. По данным Всемирного банка, масштабы экономик США и ЕС сопоставимы: в 2017 г. по паритету покупательной способности ВВП еврозоны был равен 14,9 трлн долл., а США - 19,4 трлн долл. ${ }^{4}$ При этом, по данным МВФ, доля доллара в официальных валютных резервах мира составляет $62 \%$, а евро - всего $20 \% 5$.

Американскую валюту предпочитают за минимальные издержки использования и высокую ликвидность, которые вытекают из фундаментальных основ современной глобальной валютно-финансовой системы. Именно эти основы и предстоит изменить Еврокомиссии. Для реализации поставленной цели она намерена стимулировать законодательную деятельность стран еврозоны, направленную на углубление экономического измерения интеграции; расширять сотрудничество с центральными банками других стран для поддержания финансовой стабильности и повышения доли номинированных в евро долговых инструментов, выпускаемых европейскими эмитентами; развивать экономическую дипломатию для продвижения евро на новые рынки и облегчения доступа иностранных контрагентов к платёжной системе в евро; предпринимать дополнительные меры для развития и обеспечения стабильности финансового рынка ЕС.

\footnotetext{
${ }^{1}$ State of the Union Address 2018. URL: https://ec.europa.eu/commission/priorities/state-union-speeches/state-union2018 en (дата: обращения 06.12.2018).

${ }^{2}$ Towards a stronger international role of the euro: Commission contribution to the European Council and the Euro Summit (13-14 December 2018). URL: https://ec.europa.eu/commission/publications/towards-stronger-internationalrole-euro-commission-contribution-european-council-13-14-december-2018 en (дата обращения: 06.12.2018).

${ }^{3}$ Strengthening euro's global role and tackling disinformation. URL: https://ec.europa.eu/commission/news/ strengthening-euros-global-role-and-tackling-disinformation-2018-dec-05_en (дата обращения: 06.12.2018).

${ }^{4}$ GDP, PPP (current international USD). URL: https://data.worldbank.org/indicator/NY.GDP.MKTP.PP.CD (дата обращения: 06.12.2018).

U.S. dollar share of global currency reserves fall further - IMF. URL: https://www.reuters.com/article/uk-forexreserves-idUSKBN1JR21G (дата обращения: 06.12.2018).
}

Научно-аналитический вестник ИЕ РАН, 2018, №6 
Авторы доклада видят плюсы глобального усиления европейской валюты не только для Евросоюза, но и для всей мировой финансовой системы. Они справедливо отмечают, что конечное решение об использовании той или иной валюты принимается рыночными субъектами, и цель Еврокомиссии не в том, чтобы ограничить свободу выбора валюты сделки. Цель донести до участников рынка идею о том, что рост роли евро повысит устойчивость международной финансовой системы за счёт большего разнообразия ключевых валют и снижения зависимости мировой экономики от шоков, проистекающих от действий стран-эмитентов таких валют. Европейские компании и граждане почувствуют выгоду от роста международной роли евро не только в большей защищённости от рисков, но и в снижении стоимости привлечения средств.

\section{С чего начать?}

Как и в случае с долларом в своё время, расширение глобального применения единой европейской валюты предполагается начать с повышения её роли в обслуживании торговли энергоносителями. В этой связи среди нескольких опубликованных 5 декабря документов, следует особо выделить рабочий доклад о продвижении международной роли евро в сфере энергоносителей ${ }^{1}$, который указывает на необходимость бороться с исторически сложившимся доминированием доллара США в европейской торговле углеводородами.

Сейчас операции на физическом и фьючерсном рынках нефти идут по стандартным международным маркам (Brent, WTI, Urals), которые котируются в долларах. Как следствие, европейские компании, даже между собой, ведут операции по этим позициям в долларах. По импорту природного газа ситуация немного лучше: в частности, по газу из Норвегии, есть сделки в евро. Но контракты с крупнейшим поставщиком - РФ - по-прежнему идут в доллаpax. В результате, свыше $80 \%$ импорта энергоносителей в ЕС сейчас оплачивается в долларах.

Агрессивная политика администрации Трампа, включающая в себя введение заградительных пошлин и односторонних санкций, формирует постоянный риск для тех, кто совершает операции в долларах. По сути, Европа вынуждена переосмысливать свой экономический суверенитет, важнейшей составляющей которого является укрепление статуса евровалюты. В этой связи в своём докладе Еврокомиссия говорит о необходимости противостоять действиям третьих стран, которые наносят ущерб интересам Европы, в том числе её бизнесу. В частности, речь идёт о санкциях США против Ирана, которые в сентябре 2018 г. подтолкнули политиков ЕС к обсуждению идеи создания независимой от США платёжной системы, которая бы позволила европейским компаниям покупать нефть из Ирана без угрозы отключения.

Понятно, что в Европейском союзе осознают и риск того, что санкции США против российских компаний могут заблокировать долларовые расчёты последних с европейскими партнёрами. Следовательно, под угрозой поставки энергоресурсов из РФ и крупные проекты в сфере энергетики, которые европейский бизнес реализует совместно с Россией: «Северный поток-2» и т.п.

Еврокомиссия настоятельно рекомендует странам ЕС впредь использовать евро в качестве валюты контракта во всех соглашениях о поставках энергоносителей. Кроме того, использование единой европейской валюты рекомендовано всем европейским участникам рынка в качестве валюты котировок на физическую нефть, на базе чего предполагается повысить значение производных биржевых инструментов, номинированных в евро.

\footnotetext{
${ }^{1}$ Recommendation - The international role of the euro in the field of energy. URL: https://ec.europa.eu/commission/ sites/beta-political/files/recommendation_-_the_international_role_of_the_euro_in_the_field_of_energy.pdf (дата обращения: 06.12.2018).
} 
С этой же целью будет расширяться ассортимент предлагаемых иностранным инвесторам ценных бумаг, торгуемых в евро. В частности, государствам стран еврозоны предлагается использовать их бумаги в качестве обеспечения облигаций частных эмитентов. Естественно, повышение международной роли евро невозможно без создания европейской системы платежей, независимой от подобных систем, ранее созданных американскими операторами. Для повышения глобальной роли евро потребуются и значительные сдвиги на мировом валютном рынке, где сейчас доллар используется во всех наиболее популярных валютных парах или в качестве посредника для проведения расчетов в других парах.

Помимо нефти и газа, заметную роль Еврокомиссия отводит стратегической для Старого континента отрасли - самолётостроению, где сейчас почти все платежи идут в долларах. Даже один из столпов европейской экономики и одна из крупнейших авиастроительных компаний мира, Airbus, ведёт расчёты в американской валюте. Еврокомиссия планирует начать консультации с этой и другими компаниями из чувствительных отраслей (торговля металлами, минеральным сырьём, продовольствием, железнодорожный и морской транспорт) с целью стимулирования перевода их расчётов в евро.

\section{Заключение}

О дедолларизации в последнее время говорят и в России и в Европе. Причины в обоих случаях схожие, поэтому намерение ЕС повысить роль евро в мировой экономике отчасти совпадает со стремлением РФ обезопасить себя от негативных последствий санкций США, которые могут распространиться на операции российских компаний в долларах. Тем более что РФ и ЕС являются крупными торговыми партнёрами, особенно в наиболее чувствительной для Европы сфере энергоресурсов.

Формально предпосылки для наращивания использования евро во взаимной торговле налицо. Но мировая торговля нефтью и газом исторически ведётся в долларах, и быстро изменить этот порядок не получится. И если уж и менять его сообща, то точно не в сторону ситуации, когда евро заменит доллар в этих расчётах без участия рубля.

Правда, уже упоминавшийся выше глава Счетной палаты РФ Алексей Кудрин скептически настроен по отношению к идее повышения международного значения рубля. По его убеждению, доллар играет в мировых расчётах лидирующую роль как наиболее стабильная единица измерения. Рубль же, напротив, сильно обесценивается каждый год, и переход на расчёты в нём сулит серьёзные валютные риски.

Важной точкой роста в этом отношении является укрепление валютной пары евро/ рубль, ликвидность которой заметно снизилась из-за падения рубля под ударами санкций. При этом следует помнить, что США вводят санкции именно потому, что хотят нанести удар по своим конкурентам, чьи потенциальные возможности представляют угрозу для первенства США в мировой экономике. Поэтому, даже если у ЕС и РФ и наметятся успехи на пути совместного ухода от доллара, надо быть готовыми к тому, что США будут этому сопротивляться, в том числе путём введения новых санкций.

\section{Список литературы}

Bloomberg: анкции «отобрали» у России $6 \%$ BBП. URL: http://www.banki.ru/news/lenta/?id=10750659.

Набиуллина оценила потенциал роста экономики к 2021 г. URL: https://www.rbc.ru/rbcfreenews/5bfe51a69a7947ab61e6b366?from=newsfeed.

Набиуллина рассказала о способе сделать расчёты в рублях привлекательными. URL: https://www.rbc.ru/economics/28/11/2018/5bfe4ee19a7947aa7a9c006e?from=main_right. 
State of the Union Address 2018. URL: https://ec.europa.eu/commission/priorities/state-unionspeeches/state-union-2018_en.

Towards a stronger international role of the euro: Commission contribution to the European Council and the Euro Summit (13-14 December 2018). URL: https://ec.europa.eu/commission/ publications/towardsstronger-international-role-euro-commission-contribution-european-council-13-14-december-2018_en.

Strengthening euro's global role and tackling disinformation. URL: https://ec.europa.eu/ commission/news/strengthening-euros-global-role-and-tackling-disinformation-2018-dec-05_en.

GDP, PPP (current international USD). URL: https://data.worldbank.org/indicator/NY.GDP. MKTP.PP.CD.

U.S. dollar share of global currency reserves fall further - IMF. URL: https://www.reuters.com/article/uk-forex-reserves-idUSKBN1JR21G.

Recommendation - The international role of the euro in the field of energy. URL: https://ec. europa.eu/commission/sites/beta-political/files/recommendation_-_the_international_role_of_the_ ro_in_the_field_of_energy.pdf.

\section{References}

Bloomberg: sanctzii «otobrali» u Rossii 6\% VVP. URL: http://www.banki.ru/news/lenta/?id= 10750659.

Nabiullina otzenila potentzial rosta economiki k 2021 g. URL: https://www.rbc.ru/rbcfreenews/ 5bfe51a69a7947ab61e6b366?from=newsfeed.

Nabiullina rasskazala o sposobe sdelat raschety $\mathrm{v}$ rublyah privlekatelnymi. URL: https://www.rbc.ru/economics/28/11/2018/5bfe4ee19a7947aa7a9c006e?from=main_right.

State of the Union Address 2018. URL: https://ec.europa.eu/commission/priorities/state-unionspeeches/state-union-2018_en.

Towards a stronger international role of the euro: Commission contribution to the European Council and the Euro Summit (13-14 December 2018). URL: https://ec.europa.eu/commission/ publications/towardsstronger-international-role-euro-commission-contribution-european-council-13-14-december-2018_en.

Strengthening euro's global role and tackling disinformation. URL: https://ec.europa.eu/ commission/news/strengthening-euros-global-role-and-tackling-disinformation-2018-dec-05_en.

GDP, PPP (current international USD). URL: https://data.worldbank.org/indicator/NY.GDP. MKTP.PP.CD.

U.S. dollar share of global currency reserves fall further - IMF. URL: https://www.reuters.com/article/uk-forex-reserves-idUSKBN1JR21G.

Recommendation - The international role of the euro in the field of energy. URL: https://ec.euro pa.eu/commission/sites/beta-political/files/recommendation_-_the_international_role_of_the_euro_ in_the_field_of_energy.pdf.

\section{Russia fights sanctions, while Europe fights dollar}

Author. Kirill Gusev, Leading Research Associate, Center of Monetary and Financial Studies, Institute of Europe, Russian Academy of Sciences. Address: 11-3, Mokhovaya str., Moscow, Russia, 125009. Email: banks-europe@mail.ru.

Abstract. The world economy is entering a new era: the US pressure is forcing the growing number of countries to reconsider the necessity of protecting their economic sovereignty, among other means, by reducing the international role of the US dollar in favor of greater use of their own currencies. In this context, Russia and Europe are following parallel courses now. Are the differences in their approaches critical or are there prerequisites for joining efforts of the EU and Russia?

Key words: European Union, European Commission, euro, Russia, ruble, USA, dollar, sanctions, international monetary system.

DOI: http://dx.doi.org/10.15211/vestnikieran62018165171 